\title{
Antioxidant Studies of Some Lanthanide Complexes Derived from Curcuminoid Analogues
}

\author{
MALINI PARAKKULANGARA THRITHODY ${ }^{1}$ and MUHAMMED BASHEER UMMATHUR ${ }^{2 \star}$ \\ 1Department of Chemistry, Zamorin's Guruvayurappan College, Calicut-673014, (Kerala), India. \\ 2Department of Chemistry, KAHM Unity Women's College, Manjeri-676122, (Kerala), India. \\ ${ }^{\star}$ Corresponding author E-mail: mbummathur@gmail.com
}

http://dx.doi.org/10.13005/ojc/370110

(Received: November 30, 2020; Accepted: February 16, 2021)

\section{ABSTRACT}

Antioxidant activities of the $\operatorname{Pr}(\mathrm{III}), \mathrm{Nd}(\mathrm{III}), \mathrm{Sm}$ (III), $\mathrm{Dy}(\mathrm{III}), \mathrm{Er}(\mathrm{III})$ and $\mathrm{Yb}$ (III) complexes of eight curcuminoid analogues $\left(\mathrm{HL}^{1}\right.$ to $\left.\mathrm{HL}^{8}\right)$, derived from acetylacetone and aromatic aldehydes (benzaldehyde, cinnamaldehyde, furfural, salicylaldehyde, $\beta$-hydoxy- $\alpha$-naphthaldehyde, p-anisaldehyde, p-hydroxybenzaldehyde and vanillin), are studied by the thiocyanate method. Even though all the complexes exhibited significant antioxidant properties, their activities are found to be less than the corresponding free curcuminoid analogues.

\section{Keywords: Antioxidant Studies, Thiocyanate Method, Curcuminoid Analogues, $\operatorname{Pr}(\mathrm{III}), \mathrm{Nd}(\mathrm{III}), \mathrm{Sm}(\mathrm{III}), \mathrm{Dy}(\mathrm{III}), \mathrm{Er}(\mathrm{III})$ and $\mathrm{Yb}(\mathrm{III})$ Complexes.}

\section{INTRODUCTION}

Metal complexes of many plant products are receiving much importance in recent years due to their applications in various fields ${ }^{1-3}$. The metal complexes of curcumin, a naturally occurring conjugated diketone, have been studied in detail in view of its structure and medicinal applications ${ }^{4}$. Synthetic curcuminoid analogues and their metal chelates have also been investigated by various research groups due to their applications in various biological fields ${ }^{5-11}$. Majority of these works are based on the complexes with various main group and transition metal ions. The biological applications of the lanthanide chelates of synthetic curcuminoids are not studied in detail as revealed in the literature survey. In continuation of the studies on the metal complexes of curcuminoids ${ }^{6-11}$, in this paper we report the antioxidant activities of $\operatorname{Pr}(\mathrm{III}), \mathrm{Nd}(\mathrm{III})$, Sm(III), Dy(III), Er(III) and Yb(III) complexes of curcuminoid analogues.

\section{MATERIALS AND METHODS}

All the chemicals and solvents used for the synthesis of curcuminoid analogues and their $\operatorname{Pr}(\mathrm{III}), \mathrm{Nd}(\mathrm{III}), \mathrm{Sm}(\mathrm{III}), \mathrm{Dy}(\mathrm{III}), \mathrm{Er}(\mathrm{III})$ and $\mathrm{Yb}(\mathrm{III})$ complexes were of reagent grade (Merck, Fluka and Sigma-Aldrich). For the preparation of metal complexes, Pr(III), Nd(III), Sm(III), Dy(III), Er(III) and $\mathrm{Yb}(\mathrm{III})$ nitrates were used. The antioxidant activities were studied by measuring the absorbance using a Bausch \& Lomb Spectronic 1001 UV-Visible Spectrophotometer.

This is an Open Access article licensed under a Creative Commons license: Attribution 4.0 International (CC- BY). Published by Oriental Scientific Publishing Company @ 2018

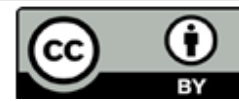


Synthesis of curcuminoid analogues and their complexes with $\operatorname{Pr}(\mathrm{III}), \mathrm{Nd}(\mathrm{III}), \mathrm{Sm}(\mathrm{III}), \mathrm{Dy}(\mathrm{III})$, $\operatorname{Er}($ III) and $\mathrm{Yb}$ (III) ions

The curcuminoid analogues ( $\mathrm{HL}^{1}-$ $\mathrm{HL}^{8}$ ) were synthesized by condensing aromatic aldehydes with acetylacetone by the methods reported in our previously published papers ${ }^{6-11}$. The aromatic aldehydes used for the condensation were benzaldehyde, cinnamaldehyde, furfural, salicylaldehyde, $\beta$-hydroxy- $\alpha$-naphthaldehyde, p-methoxybenzaldehyde, $p$-hydroxybenzaldehyde and vanillin.

$\operatorname{Pr}(I I I), N d(I I I), S m(I I I), \operatorname{Dy}(I I I), \operatorname{Er}(I I I)$ and $\mathrm{Yb}$ (III) complexes of these curcuminoid analogues were also prepared by our earlier reported methods ${ }^{12-13}$.

\section{Determination of antioxidant activities}

The thiocyanate method ${ }^{14,16}$ was employed for determining the antioxidant activity.

\section{RESULTS AND DISCUSSION}

The structure of the lanthanide chelates of curcuminoid analogues (Fig. 1) was reported

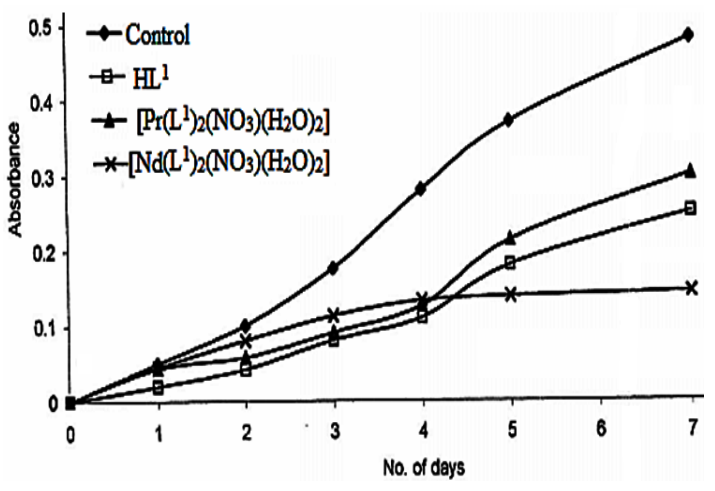

Fig. 2. Antioxidant assay of $\mathrm{HL}^{1}$ and its lanthanide chelates

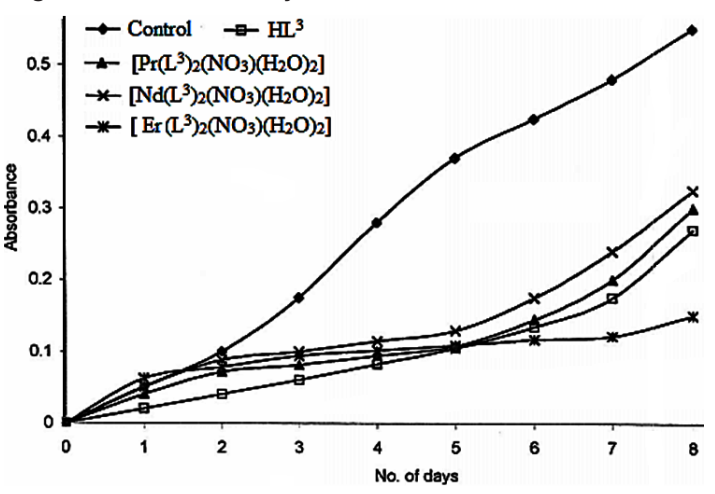

Fig. 4. Antioxidant assay of $\mathrm{HL}^{3}$ and its lanthanide chelates earlier ${ }^{12,13,15}$ based on various analytical and spectral techniques.

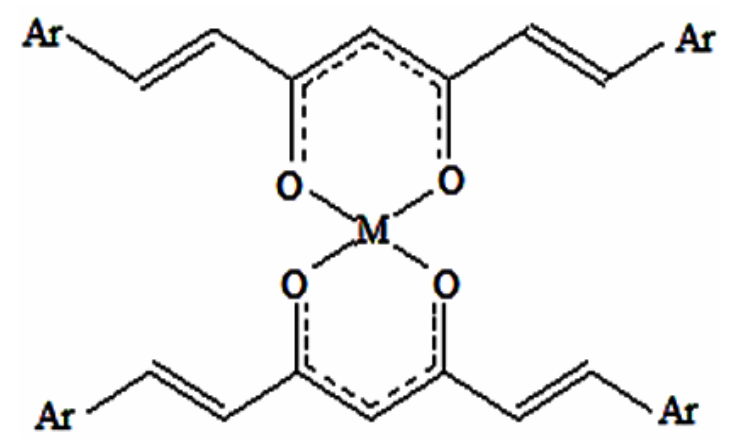

Fig. 1. Structure of the $\operatorname{Pr}($ III), Nd(III), Sm(III), Dy(III), $\operatorname{Er}($ III) and $\mathrm{Yb}(\mathrm{III})$ complexes of curcuminoid analogues; $L$ stands for the deprotonated ligand; $A r=$ phenyl $\left(L^{1}\right)$; styryl $\left(L^{2}\right)$; 2-furyl ( $\left.L^{3}\right)$; 2-hydroxyphenyl ( $\left.L^{4}\right)$; 2-hydroxy-1-naphthyl $\left(L^{5}\right)$; 4-methoxyphenyl $\left(L^{6}\right)$; 4-hydroxyphenyl $\left(L^{7}\right)$; and 4-hydroxy3-methoxyphenyl ( $\left.\mathrm{L}^{8}\right)$; M = Pr(III), Nd(III), Sm(III), Dy(III),

$\mathrm{Er}(\mathrm{III})$ and $\mathrm{Yb}(\mathrm{III})$; The proposed structure also contains one bidentate nitrate ion and two coordinated water molecules with the formula $\left[\mathrm{M}(\mathrm{L})_{2}\left(\mathrm{NO}_{3}\right)\left(\mathrm{H}_{2} \mathrm{O}\right)_{2}\right]$

The antioxidant assays of lanthanide chelates of curcuminoid analogues are shown graphically (absorbance at $500 \mathrm{~nm}$ Vs number of days) in Figure 2 to Figure 9.

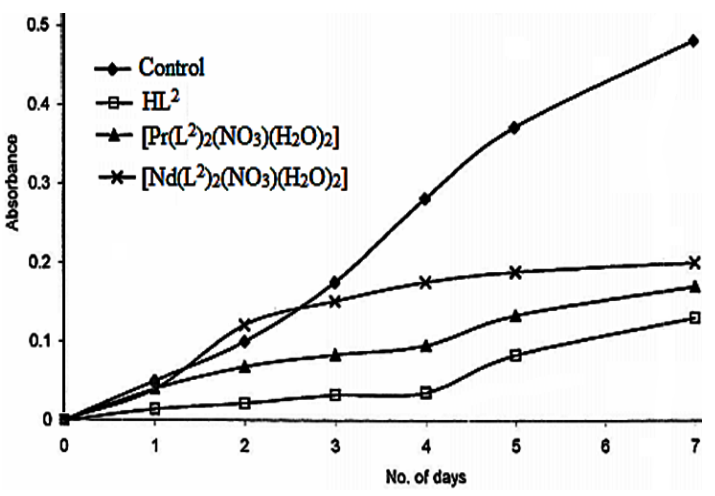

Fig. 3. Antioxidant assay of $\mathrm{HL}^{2}$ and its lanthanide chelates

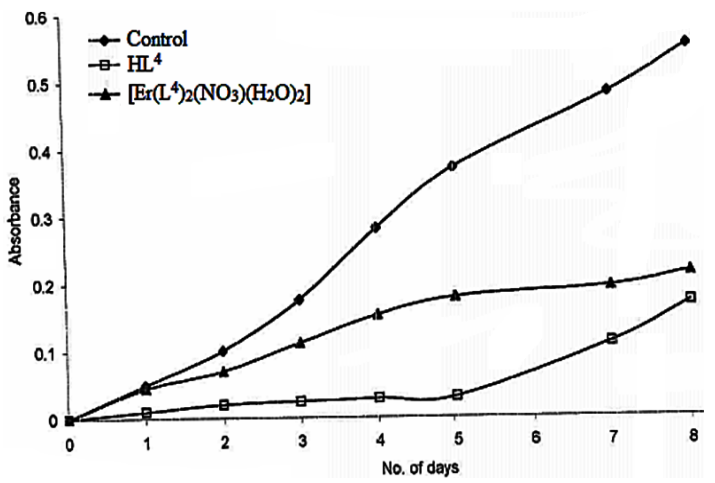

Fig. 5. Antioxidant assay of $\mathrm{HL}^{4}$ and its $\mathrm{Er}$ (III) complex 


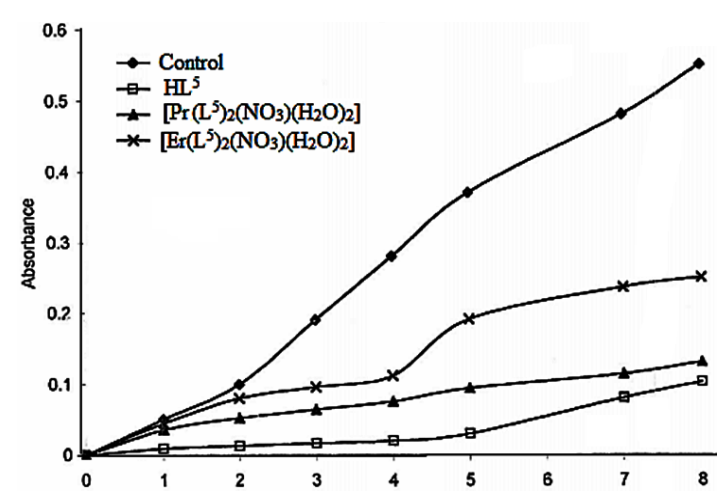

Fig. 6. Antioxidant assay of $\mathrm{HL}^{5}$ and its lanthanide chelates

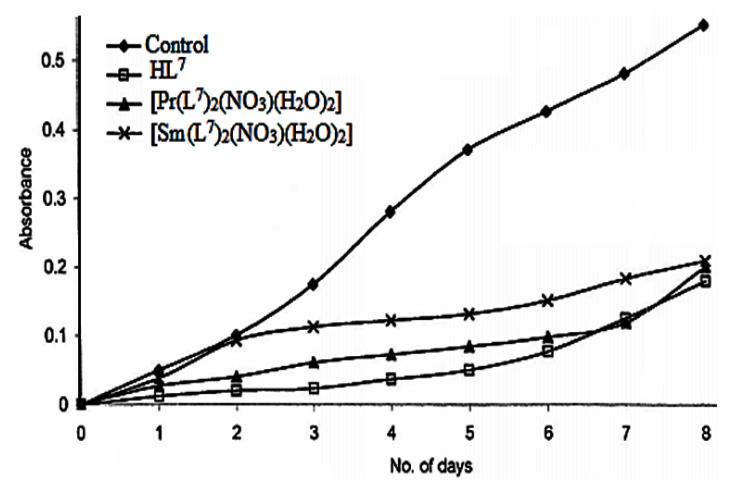

Fig. 8. Antioxidant assay of $\mathrm{HL}^{7}$ and its lanthanide chelates

The findings showed that all lanthanide chelates possess significant antioxidant activity. A comparison with the corresponding reported curcuminoid analogues ${ }^{16}$ indicates that the antioxidant activities of these lanthanide chelates are less than the corresponding free curcuminoids.

It was reported that curcuminoids having a hydroxyl group in the aryl ring show maximum antioxidant activity $6-8,10,16,17$. But the results revealed that $\mathrm{Pr}(\mathrm{III}), \mathrm{Nd}(\mathrm{III}), \mathrm{Sm}(\mathrm{III}), \mathrm{Dy}(\mathrm{III}), \mathrm{Er}(\mathrm{III})$ and $\mathrm{Yb}(\mathrm{III})$ complexes of curcuminoids which contain a hydroxyl group in the aryl ring also showed lower activity than the corresponding curcuminoid analogues. Thus it can be inferred that the $-\mathrm{OH}$ group alone is not a sufficient condition to promote antioxidant activity. This indicates the importance of free and enolised dicarbonyl moiety in imparting the antioxidant property of curcuminoids. During complexation, the enolic proton is removed with the formation of a six membered pseudo-aromatic $\mathrm{C}_{3} \mathrm{O}_{2} \mathrm{M}$ chelate ring with the metal ion, thereby losing the enolic nature of curcuminoids. Earlier reports of certain transition metal complexes of curcuminoids

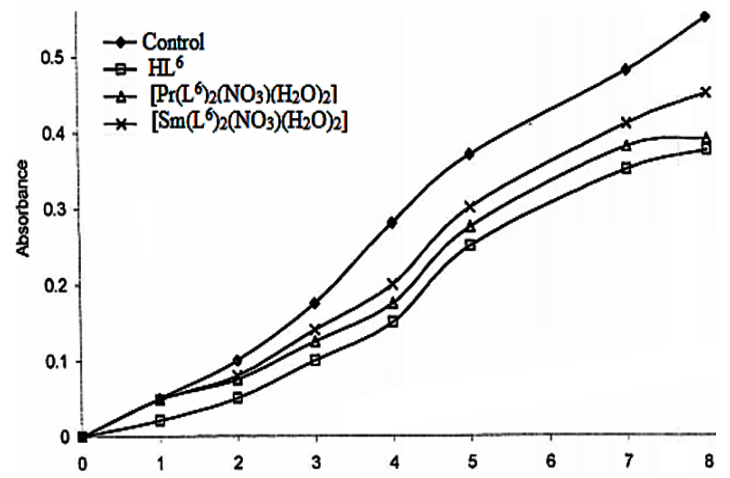

Fig. 7. Antioxidant assay of $\mathrm{HL}^{6}$ and its lanthanide chelates

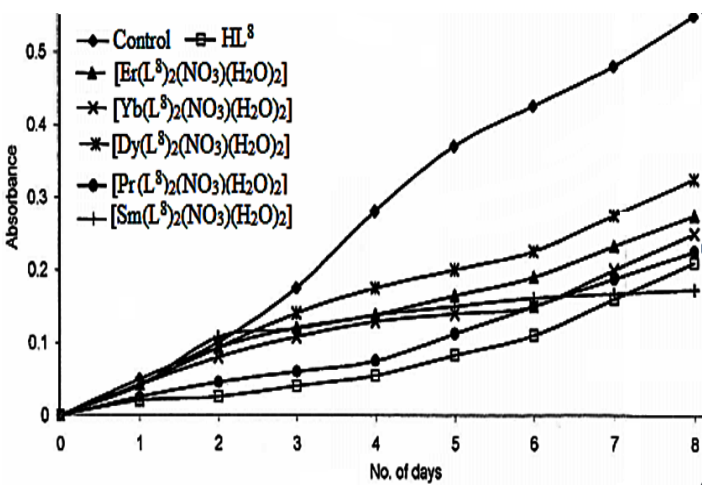

Fig. 9. Antioxidant assay of $\mathrm{HL}^{8}$ and its lanthanide chelates

also showed lesser activity than the corresponding curcuminoids ${ }^{18}$. It has been reported that the antitumour activity of curcuminoids increases on complexation with $\mathrm{Cu}(\mathrm{II})$ and $\mathrm{Al}(\mathrm{III})$ ions $^{6-10}$. The results of the present investigation clearly indicate that the antioxidant activity of curcuminoids decreases on complexation with $\operatorname{Pr}($ III), $\mathrm{Nd}(\mathrm{III}), \mathrm{Sm}(\mathrm{III}), \mathrm{Dy}(\mathrm{III}), \mathrm{Er}(\mathrm{III})$ and $\mathrm{Yb}$ (III) ions.

\section{CONCLUSION}

The effects of complexation of $\operatorname{Pr}(\mathrm{III})$, $\mathrm{Nd}(\mathrm{III}), \mathrm{Sm}(\mathrm{III}), \mathrm{Dy}(\mathrm{III}), \mathrm{Er}(\mathrm{III})$ and $\mathrm{Yb}$ (III) ions on the antioxidant properties of curcuminoid analogues were studied. Even though all the lanthanide chelates exhibited significant antioxidant activity, the metal complexation lowered the activities of all the curcuminoids. The results revealed that the enolised and intramolecularly hydrogen bonded dicarbonyl moiety is mainly responsible for the antioxidant property of all curcuminoids. The decrease in the antioxidant property during complex formation arises due to the replacement of this intramolecularly hydrogen bonded enolic proton by metal cation. 


\section{ACKNOWLEDGEMENT}

The authors express sincere thanks to University Grants Commission, New Delhi, India for providing financial assistance; and Department of Life Sciences, University of Calicut, India for providing facilities for the antioxidant studies.

\section{Conflicts of Interest}

No conflict of interest regarding this article.

\section{REFERENCES}

1. Castillo-Blum, S. E.; Barba-Bahrens, N. Coord. Chem. Rev., 2000, 196(1), 3-30.

2. Singh, R. V.; Srivastava, S. J. Ind. Chem. Soc., 2013, 90(6), 711-737.

3. Cotruvo, J. A. ACS Cent. Sci., 2019, 5(9), 1496-1506.

4. Shakeri, A.; Panahi, Y.; Johnston, T.P.; Sahebkar, A. BioFactors., 2019, 45(3), 304-317.

5. Calinescu, M.; Fiastru, M.; Bala, D.; Mihailciuc, C.; Negreanu-Pîrjol, T.; Jurca, B. J. Saudi Chem. Soc., 2019, 23(7), 817-827.

6. John, V. D.; Ummathur, M. B.; Krishnankutty, K. J. Coord. Chem., 2013, 66(9), 1508-1518.

7. John, V. D.; Krishnankutty, K. Appl. Organometal. Chem., 2006, 20(8), 477-482.

8. John, V. D.; Krishnankutty, K. Trans. Met. Chem., 2005, 30, 229-233.

9. Krishnankutty, K.; John, V. D. Synth. React. Inorg. Met.-Org. Chem., 2003, 33, 343-358.

10. John, V. D.; Kuttan, G.; Krishnankutty, K. J. Exp.
Clin. Cancer Res., 2002, 21(2), 219-224.

11. Krishnankutty, K.; Venugopalan, P. Synth. React. Inorg. Met-Org. Chem., 1998, 28, 1313-1325.

12. Malini, P. T.; Ummathur, M. B. J. Appl. Sci. Comput., 2020, 7(9), 72-75.

13. Malini, P.T.; Ummathur, M. B.; Krishnankutty, K. J. Appl. Sci. Comput., 2020, 7(10), 163-166.

14. Ak, T.; Gülçin, I. Chem. Biol. Interact., 2008, 174(1), 27-37.

15. Malini, P. T.; Ummathur, M. B.; Krishnankutty, K. J. Appl. Sci. Comput., 2020, 7(11), 10-13.

16. Malini, P.T.; Ummathur, M. B.; Krishnankutty, K. Int. J. Recent Sci., 2020, 11, 40089-40091.

17. Weber, W. M.; Hunsaker, L. A.; Abcouwer, S. F.; Deck, L. M.; Vander Jagt, D. L. Bioorg. Med. Chem., 2005, 13(11), 3811-3820.

18. Priya, R. S.; Balachandran, S.; Joseph, D.; Mohanan, P. V. Univ. J. Phys. Appl., 2015, 3(1), 6-16. 